\title{
Expression of K19 and K7 in dysplastic nodules and hepatocellular carcinoma
}

\author{
JUN SANG BAE ${ }^{1 *}$, HANA CHOI $^{1 *}$, SANG JAE NOH ${ }^{1}$, BYUNG HYUN PARK $^{2}$, \\ KYU YUN JANG ${ }^{1}$, CHEOL KEUN PARK ${ }^{3}$ and WOO SUNG MOON ${ }^{1}$ \\ Departments of ${ }^{1}$ Pathology and ${ }^{2}$ Biochemistry, Chonbuk National University, Medical School and Research Institute \\ for Endocrine Sciences, Jeonju, 561-756; ${ }^{3}$ Samsung Medical Center, Sungkyunkwan \\ University School of Medicine, Seoul 135-701, Republic of Korea
}

Received January 16, 2012; Accepted May 21, 2012

DOI: $10.3892 / \mathrm{ol} .2012 .731$

\begin{abstract}
Hepatocellular carcinoma (HCC) is one of the most common types of malignant tumors characterized by a multistep process of tumor development. Nodular lesions that differ from the surrounding liver parenchyma and are characterized by cytological or structural atypia are termed dysplastic nodules (DNs). DNs are well-known precancerous HCC lesions. Expression of keratin (K) 19 and K7, molecular markers of hepatic progenitor cells and cholangiocytes, has been reported in certain HCCs. However, it remains unclear whether K19-positive HCC cells are derived from true hepatic progenitor cells or mature cells that have undergone a dedifferentiation or a transdifferentiation process. In total, 107 tissue sections (13 low-grade DNs, 15 high-grade DNs, 27 small HCCs and 52 large HCCs) from resected liver samples and $132 \mathrm{HCC}$ tissue microarray (TMA) cores were subjected to immunohistochemical analysis for K19 and K7. Clinicopathological data of the HCC patients were evaluated. K19 expression was found in $0 \%$ of DNs, $19 \%$ of small HCCs $(\leq 2 \mathrm{~cm}), 8 \%$ of large HCCs $(>2 \mathrm{~cm})$ and $8 \%$ of TMA samples. $\mathrm{K} 7$ expression was found in $14 \%$ of DNs, $41 \%$ of small HCCs, $15 \%$ of large HCCs and 6\% of TMA samples. Among the five K19-positive small HCCs, four were distinctly nodular and one tumor was an infiltrative type. No vaguely nodular $\mathrm{HCC}$ was positive for K19. K19 expression was significantly associated with histological grade $(\mathrm{P}=0.023)$, serum $\alpha$-fetoprotein level $(\mathrm{P}=0.001)$ and $\mathrm{K} 7$ expression $(\mathrm{P}=0.001)$ in HCC. $\mathrm{K} 19$ expression was an independent prognostic factor for overall survival in non-viral HCC patients $(\mathrm{P}=0.003)$. K19 expression is extremely rare in DNs and occurs in progressed small HCCs. Our results suggest
\end{abstract}

Correspondence to: Professor Woo Sung Moon, Department of Pathology, Chonbuk National University, Medical School, Jeonju 561-756, Republic of Korea

E-mail: mws@chonbuk.ac.kr

*Contributed equally

Key words: carcinoma, hepatocellular, keratin, dysplastic nodule that K19 expression may be an acquired feature of carcinoma cells during HCC progression in certain HCCs.

\section{Introduction}

Hepatocellular carcinoma (HCC) is the sixth most common type of solid malignant tumor worldwide, and both the incidence and mortality rates have increased in recent years $(1,2)$. The development of HCC usually follows a multistep sequence, and de novo development of HCC appears to be rare. The carcinogenic sequence of chronic hepatitis, cirrhosis, dysplastic nodule (DN) and HCC has been well-established (3). Nodular lesions that differ from the surrounding liver parenchyma and that are characterized by cytological or structural atypia are termed DNs. DN is a well-known precancerous lesion of HCC. DNs are classified as low-grade (LGDN) or high-grade (HGDN) depending on the degree of atypia $(3,4)$.

Keratin 19 (K19) and K7, molecular markers of hepatic progenitor cells and cholangiocytes, are expressed in a proportion of HCCs $(5,6)$. K19 expression in HCC is associated with recurrence, metastasis and poor prognosis (5-8). Recent studies have postulated that K19-positive HCCs originates from hepatic progenitor cells (HPCs) $(5,9,10)$. However, it remains unknown whether K19-positive HCCs are generated through the carcinogenesis of K19-positive HPCs or whether K19 expression in HCC may be the result of dedifferentiation during HCC progression. If K19-positive HCCs arise from HPCs, HPC would be expected to already be present in precursor HCC lesions. Clarifying the histogenesis of $\mathrm{K} 19$-positive $\mathrm{HCC}$ is significant, as it may provide a rationale for novel therapeutic approaches to HCC.

Therefore, in the present study, we examined K19 and $\mathrm{K} 7$ expression in $27 \mathrm{DNs}$ and $79 \mathrm{HCC}$ tissue sections from resected liver samples and $132 \mathrm{HCC}$ tissue microarrays (TMA). We also analyzed the clinicopathological characteristics of these HCCs.

\section{Patients and methods}

Patients. The total 107 samples consisted of preoperatively untreated tissue sections surgically resected (13 LGDNs, 15 HGDNs and 79 HCCs) between September 2004 and 
August 2008 at the Chonbuk National University Hospital and Samsung Medical Center, Korea. This study was approved by the Ethics Committees of Chonbuk National University and Samsung Medical Center. Group 1 HCCs were comprised 27 small HCCs $(\leq 2 \mathrm{~cm})$ and 52 advanced HCCs $(>2 \mathrm{~cm})$. Of the 27 small HCCs, 5 were vaguely nodular, 20 were distinctly nodular and 2 were infiltrative types. Representative $4-\mu \mathrm{m}$ sections were prepared from $10 \%$ formalin-fixed, paraffin-embedded tissue samples for immunohistochemical staining. In each case, clinicopathological characteristics, such as patient age at diagnosis, gender, etiology, serological data, including $\alpha$-fetoprotein (AFP) and albumin levels, background liver disease, tumor size, Edmonson-Steiner grade, microvessel invasion, presence of intrahepatic metastasis and ascites, as well as follow-up data were obtained from hospital records. Tumors were staged according to the 2010 American Joint Committee on Cancer tumor-node-metastasis classification (11). The follow-up period was determined from the date of initial surgery until the date of the last follow-up or death.

TMA construction. We constructed TMA slides (Superbiochips Laboratories, Seoul, Korea) to compare the concordance rates of K19 and K7 expression in HCC between whole sections and TMA. After screening, hematoxylin and eosin-stained slides, cores measuring $3 \mathrm{~mm}$ in the greatest dimension, were obtained from 132 representative paraffin-embedded HCC blocks, which were resected at the Chonbuk National University Hospital between January 1998 and December 2009. A subset of 36 HCCs from the 79 whole-tissue sections was compared with the corresponding TMA samples.

Immunohistochemistry. Immunohistochemical staining for K19 and K7 (Dako, Carpinteria, CA, USA) was performed as previously described (12). Samples demonstrating membrane and cytoplasmic staining of at least $5 \%$ of tumor cells were defined as positive (5). Positive immunoreactivity in whole tissue sections was classified as: diffuse pattern, $>50 \%$ of tumor cells were positive; geographic pattern, $5-49 \%$ were positive.

Statistical analysis. Comparisons between K19 or K7 expression and clinicopathological factors were assessed by the Chi-square test. Survival analyses were performed using the Kaplan-Meier method, and differences in survival between the various clinical groups were determined by the log-rank test. A Cox proportional hazards regression analysis was performed to estimate the impact of clinicopathological factors on patient survival. $\mathrm{P}<0.05$ was considered to indicate a statistically significant difference. SPSS version 15.0 statistical software (SPSS Inc., Chicago, IL, USA) was used for the statistical analysis.

\section{Results}

Clinical characteristics. The 175 patients with HCC were aged between 25 and 79 years old and comprised 146 males and 29 females. A total of 126 patients were positive for hepatitis B virus surface antigen; 22 were alcohol-related, 10 were positive for anti-hepatitis $\mathrm{C}$ virus antibody and 17 patients were of unknown etiology (Table I).
Immunohistochemical results. Reactive ductular cells surrounding an inflamed portal tract were positive for K19 and/or K7 in cirrhotic livers (Fig. 1A and B). Of $28 \mathrm{DNs}$, 24 were K7-/K19- (86\%), four were K7+/K19- (14\%) and none were K7-/K19+ or K7+/K19+. Of the four K7-positive DNs, three were LGDNs and one was HGDN. The K7-positive DNs demonstrated a geographic staining pattern $(<30 \%$ of tumor cells) with accentuated staining in intermediate hepatocyte-like cells around portal tracts in LGDNs (Fig. 1C and D). These K7-positive and K19-negative cells in DNs may be associated with intermediate hepatocyte-like cells. Of the 79 whole HCC sections, K19 expression was detected in $9(11 \%)$ HCCs, including the diffuse pattern in 8 cases and the geographic pattern in 2 cases (Fig. 1E and F). Nineteen of the 79 (24\%) HCCs were positive for K7, the diffuse pattern was found in 5 cases and the geographic pattern was found in 14 cases. Among 27 small HCCs, 15 were K7-/K19- (56\%), 7 were $\mathrm{K} 7+/ \mathrm{K} 19-(26 \%)$, one was K7-/K19+ (4\%) and four were $\mathrm{K} 7+/ \mathrm{K} 19+(15 \%)$. Among the five K19-positive small HCCs, four were distinctly nodular and one was infiltrative type. No vaguely nodular HCC was positive for K19. Of 11 K7-positive small HCCs, two were vaguely nodular, eight were distinct nodular and one was infiltrative type. In progressed HCC, 42 were K7-/K19- (81\%), six were K7+/K19- (12\%), two were $\mathrm{K} 7-/ \mathrm{K} 19+(4 \%)$ and two were $\mathrm{K} 7+/ \mathrm{K} 19+(4 \%)$. Similar to a previous study (5), HCC cells reactive to K7 and/or K19 were mostly small or intermediate-sized cells, but smaller than the non-neoplastic hepatocytes in the tissue surrounding the tumor. The K19 expression pattern in HCC was more homogeneous and diffuse compared with that of K7. Of the 132 TMA samples, 116 were K7-/K19- (88\%), five were K7+/K19- (4\%), eight were K7-/K19+ (6\%) and three were K7+/CK19+ (2\%). In the validation study between the whole section and TMA samples, the concordance rates for K7 and K19 staining in HCC were $81 \%$ (29 of 36) and 89\% (32 of 36), respectively. Five K7-positive HCCs in whole sections changed to negative cases in TMA samples, while two K19-positive cases changed to negative cases in TMA samples. The frequencies of K19 and/or K7-positive HCC decreased in small HCC, large HCC and TMA samples, respectively (Table II).

Correlation between immunohistochemical results and clinicopathological characteristics. To elucidate the significance of K19 and K7 in HCCs, we correlated their protein expression with major clinicopathological variables (Table I). The clinicopathological analysis demonstrated that K19-positive HCC was significantly associated with high histological grade $(\mathrm{P}=0.023)$, serum AFP level $(\mathrm{P}=0.001)$ and $\mathrm{K} 7$ expression $(\mathrm{P}=0.001)$. Other factors, including age, gender, etiology, background liver disease, albumin level, presence of intrahepatic metastasis, microvessel invasion and presence of ascites were not correlated with K19 expression. No significant differences were observed between K7-positive and K7-negative HCC with regard to any clinicopathological parameters.

Patient outcomes. The follow-up intervals ranged from 1 to 142 months. Sixty-one patients died during the follow-up period. The median survival of patients with K19-positive HCC was 82.0 months. The median survival of patients with K19-negative HCC was 87 months. The 5-year survival rate in 
Table I. Association between pathological features and K19-positive patients with HCC.

\begin{tabular}{|c|c|c|c|c|c|c|c|c|c|}
\hline \multirow[b]{2}{*}{ Characteristics } & \multicolumn{3}{|c|}{ Overall HCC $(n=175)$} & \multicolumn{3}{|c|}{ Non-viral HCC $(n=39)$} & \multicolumn{3}{|c|}{ Viral HCC $(n=136)$} \\
\hline & Total & K19+ & P-value & Total & K19+ & P-value & Total & K19+ & P-value \\
\hline \multicolumn{10}{|l|}{ Gender } \\
\hline Male & 146 & 13 & 0.062 & 33 & 2 & 0.003 & 113 & 11 & 0.634 \\
\hline Female & 29 & 6 & & 6 & 3 & & 23 & 3 & \\
\hline \multicolumn{10}{|l|}{ Age (years) } \\
\hline$<55$ & 66 & 6 & 0.632 & 7 & 0 & 0.263 & 57 & 6 & 0.940 \\
\hline$\geq 55$ & 109 & 13 & & 32 & 5 & & 79 & 8 & \\
\hline \multicolumn{10}{|l|}{ Liver cirrhosis } \\
\hline Absence & 85 & 7 & 0.279 & 22 & 2 & 0.428 & 63 & 5 & 0.401 \\
\hline Presence & 90 & 12 & & 17 & 3 & & 73 & 9 & \\
\hline \multicolumn{10}{|l|}{ Ascites } \\
\hline Absence & 158 & 18 & 0.488 & 33 & 5 & 0.307 & 125 & 13 & 0.891 \\
\hline Presence & 17 & 1 & & 6 & 0 & & 11 & 1 & \\
\hline \multicolumn{10}{|l|}{ Albumin (g/dl) } \\
\hline$\geq 3.5$ & 151 & 18 & 0.257 & 34 & 5 & 0.358 & 117 & 13 & 0.437 \\
\hline$<3.5$ & 24 & 1 & & 5 & 0 & & 19 & 1 & \\
\hline \multicolumn{10}{|c|}{ Preoperative AFP (ng/ml) } \\
\hline$<100$ & 115 & 6 & 0.001 & 32 & 3 & 0.169 & 83 & 3 & 0.001 \\
\hline$\geq 100$ & 60 & 13 & & 7 & 2 & & 53 & 11 & \\
\hline \multicolumn{10}{|c|}{ Intrahepatic metastasis } \\
\hline Absence & 119 & 13 & 0.967 & 30 & 4 & 0.170 & 89 & 9 & 0.516 \\
\hline Presence & 56 & 6 & & 9 & 1 & & 47 & 5 & \\
\hline \multicolumn{10}{|c|}{ Microvessel invasion } \\
\hline Absence & 75 & 7 & 0.575 & 17 & 2 & 0.862 & 58 & 5 & 0.580 \\
\hline Presence & 100 & 12 & & 22 & 3 & & 78 & 9 & \\
\hline \multicolumn{10}{|c|}{ Histological grade } \\
\hline 1 and 2 & 98 & 6 & 0.023 & 23 & 2 & 0.356 & 75 & 4 & 0.035 \\
\hline 3 and 4 & 77 & 13 & & 16 & 3 & & 61 & 10 & \\
\hline \multicolumn{10}{|l|}{ pT stage } \\
\hline 1 & 69 & 6 & 0.651 & 16 & 2 & 0.974 & 53 & 4 & 0.518 \\
\hline 2 & 72 & 8 & & 14 & 2 & & 58 & 6 & \\
\hline 3 and 4 & 34 & 5 & & 9 & 1 & & 25 & 4 & \\
\hline \multicolumn{10}{|l|}{ Etiology } \\
\hline Viral & 136 & 14 & 0.655 & & & & & & \\
\hline Non-viral & 39 & 5 & & & & & & & \\
\hline
\end{tabular}

$\mathrm{K}$, keratin; HCC, hepatocellular carcinoma.

patients with K19-positive HCC was lower (52\%) than that of patients with K19-negative HCC (55\%). In a univariate analysis, intrahepatic metastasis, serum albumin levels, microvessel invasion and $\mathrm{pT}$ stage were significantly associated with poor patient survival $(\mathrm{P}<0.001, \mathrm{P}=0.010, \mathrm{P}=0.030, \mathrm{P}=0.031$, respectively). The multivariate analysis revealed that intrahepatic metastasis and serum albumin levels were independent prognostic indicators $(\mathrm{P}=0.002, \mathrm{P}=0.001$, respectively) (Table III). In non-viral HCC patients, the median survival of patients with K19-positive HCC was 33 months. K19 expression was significantly associated with patient survival in non-viral HCC patients in univariate and multivariate Cox survival analyses ( $\mathrm{P}=0.028, \mathrm{P}=0.003$, respectively) (Table IV; Fig. 2). No survival difference was observed between patients with K7-positive and K7-negative HCC.

\section{Discussion}

Keratins are cytoskeletal intermediate filaments present in both normal and malignant epithelial cells (13). In normal livers, hepatocytes express K8 and K18, while biliary cells also contain K7 and K19 $(14,15)$. As this keratin phenotype is considered to be preserved during neoplastic transformation, HCC would be expected to express K8 and K18, but 


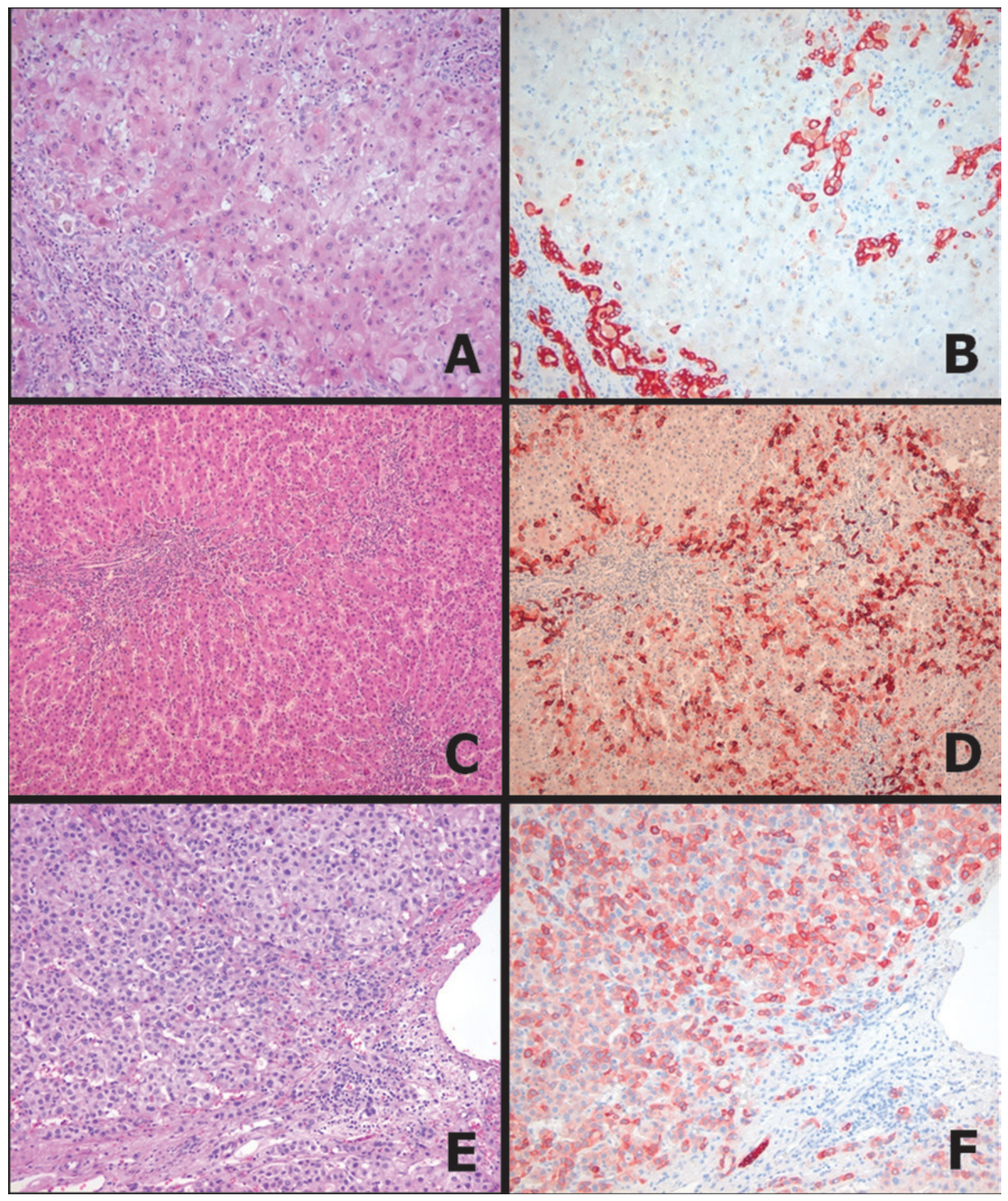

Figure 1. Hematoxylin and eosin staining and immunohistochemical results of K19 and K7 expression in cirrhotic liver, DNs and HCC. (A and B) Ductular cells surrounding the portal tract and in the interface between hepatocytes and stroma demonstrated strong K19 immunoreactivity in cirrhotic livers are shown. (C and D) K7 expression in low-grade DN is shown. K7 demonstrated a geographic pattern of intermediate hepatocyte-like cells and small cells in low-grade DNs. (E and F) K19 immunoreactivity shows small HCC cells with diffuse and intense cytoplasmic reactivity. K, keratin; DN, dysplastic nodules; HCC, hepatocellular carcinoma.

not K7 or K19 (14,15). K19 is a marker of biliary cells and hepatic progenitor cells, while $\mathrm{K} 7$ is expressed in intermediate hepatocyte-like cells, biliary cells and progenitor cells (16). Several studies have demonstrated that K19 expression in HCCs and K19-positive HCCs have a high recurrence and metastasis rates, which are associated with a poor prognosis (5-8). Although the clinical significance of K19-positive HCC appears to be established, the mechanism underlying the development of K19-positive HCC remains unclear. The presence of K19-positive tumor cells in HCC may be explained by two distinct mechanisms: either the cell of origin is a progenitor cell or the tumors dedifferentiated and acquired the K19 phenotype during carcinogenesis. When progenitor cells are the cells of origin of K19-positive HCCs, it is expected that the premalignant precursor lesions consist of K19-positive cells and their progeny.

We found for the first time that K19 expression was extremely rare in DNs, but appeared in the distinctly nodular type of small HCC. Small HCC is defined as a carcinoma that measures $\leq 2 \mathrm{~cm}$ in diameter. There are two types of 
Table II. Expression rate of K19 and K7 in DNs, small HCC, large HCC and TMA samples.

\begin{tabular}{|c|c|c|c|c|}
\hline Keratin & $\mathrm{DN}(\%)$ & Small HCC (\%) & Large HCC (\%) & TMA section (\%) \\
\hline 7 & $4 / 28(14)$ & $11 / 27(41)$ & $8 / 52(15)$ & $8 / 132(6)$ \\
\hline 19 & $0 / 28(0)$ & $5 / 27(19)$ & $4 / 52(8)$ & $10 / 132(8)$ \\
\hline
\end{tabular}

K, keratin; DN, dysplastic nodules; HCC, hepatocellular carcinoma; TMA, tissue microarray.

Table III. Cox proportional hazard analyses of factors associated with HCC in 175 patients.

\begin{tabular}{|c|c|c|c|c|c|c|c|}
\hline & \multicolumn{4}{|c|}{ Univariate model } & \multicolumn{3}{|c|}{ 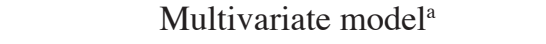 } \\
\hline & No. of patients (\%) & HR & $95 \% \mathrm{CI}$ & P-value & HR & $95 \% \mathrm{CI}$ & P-value \\
\hline \multicolumn{8}{|c|}{ Albumin $(\mathrm{g} / \mathrm{dl})$} \\
\hline$\geq 3.5$ & $151(86.3)$ & 2.330 & $1.229-4.418$ & 0.010 & 3.061 & $1.575-2.885$ & 0.001 \\
\hline$<3.5$ & 24 (13.7) & & & & & & \\
\hline \multicolumn{8}{|c|}{ Intrahepatic metastasis } \\
\hline Absence & $119(68.0)$ & 2.690 & $1.627-4.499$ & $<0.001$ & 2.503 & $1.407-4-453$ & 0.002 \\
\hline Presence & $56(32.0)$ & & & & & & \\
\hline \multicolumn{8}{|c|}{ Microvessel invasion } \\
\hline Absence & 75 (42.9) & 1.823 & $1.060-3.136$ & 0.030 & & & \\
\hline Presence & $100(57.1)$ & & & & & & \\
\hline \multicolumn{8}{|l|}{ pT stage } \\
\hline 1 & $69(39.4)$ & & & 0.031 & & & \\
\hline 2 & $72(41.1)$ & 2.214 & $1.206-4.065$ & 0.010 & & & \\
\hline 3 and 4 & $34(19.5)$ & 2.026 & $1.000-4.107$ & 0.050 & & & \\
\hline \multicolumn{8}{|l|}{ K19 } \\
\hline Negative & $156(89.1)$ & 0.997 & $0.454-2.193$ & 0.995 & & & \\
\hline Positive & $19(10.9)$ & & & & & & \\
\hline \multicolumn{8}{|l|}{ K7 } \\
\hline Negative & $148(84.6)$ & 0.880 & $0.417-1.858$ & 0.737 & & & \\
\hline Positive & $27(15.4)$ & & & & & & \\
\hline \multicolumn{8}{|l|}{ Etiology } \\
\hline Viral & $136(77.7)$ & 1.265 & $0.658-2.430$ & 0.481 & & & \\
\hline Non-viral & $39(22.3)$ & & & & & & \\
\hline
\end{tabular}

aVariables considered in the analyses were age, gender, serum albumin levels, intrahepatic metastasis, microvessel invasion, pT stage, K7 and K19 expression. HCC, hepatocellular carcinoma; K, keratin.

small HCCs; vaguely nodular and distinctly nodular. Vaguely nodular HCC is early HCC, and distinctly nodular HCC is small progressed HCC $(3,4)$. Contrary to the hypothesis that K19-positive HCC originates from hepatic progenitor cells, our results suggest that HCCs could obtain the K19 phenotype during a small progressed stage of HCC. Our findings are consistent with the results of Libbrecht et al who reported the absence of K19 expression in small cell dysplastic foci, the earliest premalignant lesions known thus far in human $\mathrm{HCC}$, although these authors suggested that differentiating putative progenitor cells gives rise to small cell dysplasia foci (16). The keratin expression pattern in HCC might not always be preserved, and aberrant K19 and/or K7 expression is observed during HCC dedifferentiation (17). Furthermore, in a study of HCC cell lines with different metastatic potentials established from the same parent cell line, K19 demonstrated a consistently increased expression from a low metastatic to a high metastatic cell line (18). Taken together, our data suggest that K19 expression is likely an acquired feature of carcinoma cells during HCC progression in certain HCCs, although the presence of cancer stem cells may be another contributor to K19-positive HCC.

Previous studies have demonstrated that epidermal growth factor (EGF) and hepatocyte growth factor (HGF) are potent inducers of the biliary phenotype in rat hepatocytes $(19,20)$. Yoneda et al have reported that activation of the EGF receptor 
Table IV. Cox proportional hazard analyses of factors associated with non-viral HCC in 39 patients.

\begin{tabular}{|c|c|c|c|c|c|c|c|}
\hline & \multicolumn{4}{|c|}{ Univariate model } & \multicolumn{3}{|c|}{ Multivariate model $^{\mathrm{a}}$} \\
\hline & $\mathrm{N}(\%)$ & HR & $95 \% \mathrm{CI}$ & P-value & HR & $95 \% \mathrm{CI}$ & P-value \\
\hline \multicolumn{8}{|c|}{ Albumin $(\mathrm{g} / \mathrm{dl})$} \\
\hline$\geq 3.5$ & $34(87.2)$ & 2.108 & $0.437-10.173$ & 0.353 & 9.148 & $1.201-69.698$ & 0.033 \\
\hline$<3.5$ & $5(12.8)$ & & & & & & \\
\hline \multicolumn{8}{|c|}{ Intrahepatic metastasis } \\
\hline Absence & $30(76.9)$ & 3.618 & $0.988-13.248$ & 0.052 & 8.560 & $1.707-42.933$ & 0.009 \\
\hline Presence & $9(23.1)$ & & & & & & \\
\hline \multicolumn{8}{|l|}{ pT stage } \\
\hline 1 & $16(41.0)$ & & & 0.938 & & & \\
\hline 2 & 14 (35.9) & 0.772 & $0.183-3.261$ & 0.725 & & & \\
\hline 3 and 4 & $9(23.1)$ & 0.958 & $0.221-4.181$ & 0.958 & & & \\
\hline \multicolumn{8}{|l|}{ K19 } \\
\hline Negative & $34(87.2)$ & 4.713 & $1.327-16.738$ & 0.028 & 10.047 & $2.218-45.506$ & 0.003 \\
\hline Positive & $5(12.8)$ & & & & & & \\
\hline \multicolumn{8}{|l|}{ K7 } \\
\hline Negative & $32(82.1)$ & 2.257 & $0.564-9.038$ & 0.250 & & & \\
\hline Positive & 7 (17.9) & & & & & & \\
\hline
\end{tabular}

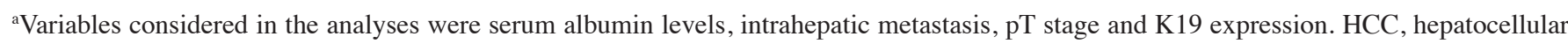
carcinoma; K, keratin.
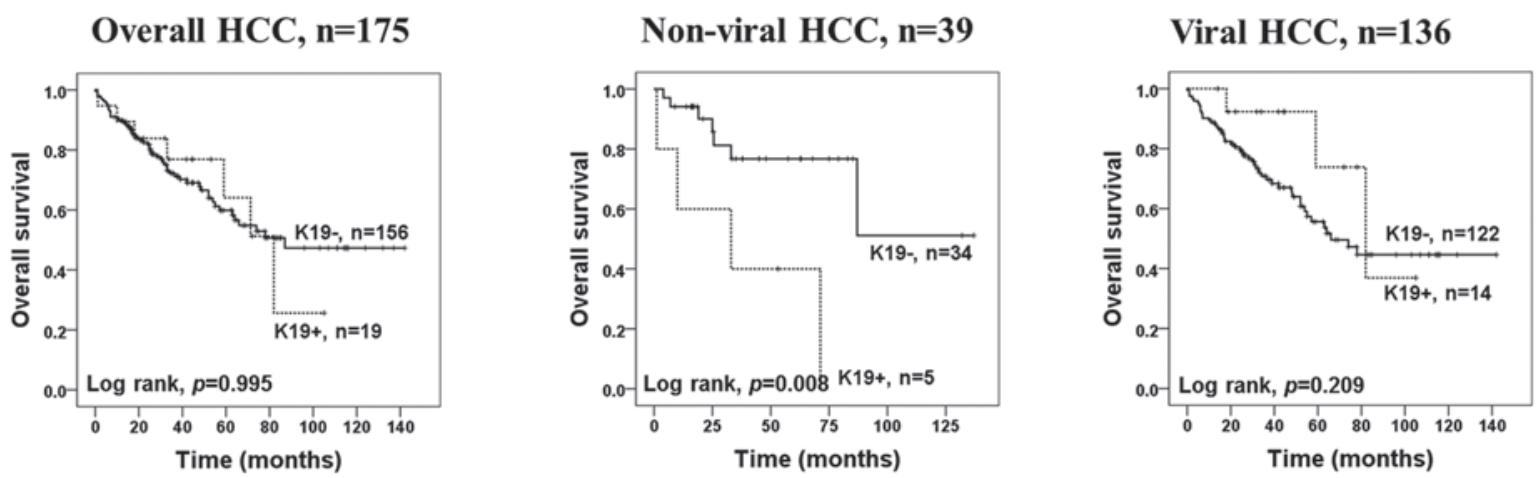

Figure 2. Kaplan-Meier analysis of overall survival in patients with K19-positive HCC. HCC, hepatocellular carcinoma; K, keratin.

signaling pathway is associated with the development of K19-positive HCC, and that the EGF-induced increase in the growth abilities of HCC account for the poor patient prognosis (21). Transarterial chemoembolization (TACE) induces a more aggressive type of HCC characterized by a biliary phenotype $(22,23)$. Nishihara et al have suggested the HCC with biliary phenotype originates from the adaptive transformation of the unaffected or TACE-resistant tumor cell population (24). It was initially reported that the cancer stem cell model is essentially synonymous with the hierarchy model of carcinogenesis (25). However, stemness-related marker expression exists as a functional phenotype in the stochastic (dedifferentiation) model and could be demonstrated by any member of the malignant population in the presence of the appropriate endogenous and exogenous factors (26). Taken together, K19 expression might be induced in specific HCCs after being stimulated by a certain type of growth factor or under certain growth conditions, accounting for the development of K19-positive HCCs.

This study has demonstrated that K19 and K7 expression were observed in 11 and $24 \%$ of our 79 patients with HCC, respectively. This expression proportion was similar to earlier studies reporting K19 or K7 in 10-50\% of HCCs, despite geographic differences, different carcinogens and genetic backgrounds $(5-7,9,27-29)$. In this study, we found that the K19 and K7 positivity rate was highest in small HCCs and decreased in advanced large HCCs. The reason for the decreased K19 and/or K7 immunoreactivity in patients with advanced HCC is unclear. The majority of the small HCCs could be examined completely for immunohistochemical 
staining, while only a small part of the large HCCs were examined, which may be a possible explanation for this finding. The finding that a large proportion of the K19 and/or K7-positive HCCs demonstrated a heterogeneous or focal staining pattern supports this hypothesis. Discrepancies in the immunohistochemical results for keratin expression between representative whole tissue sections and TMA in the present study may also have been caused by a similar reason. As K19 and/or K7-positive HCC cells were not diffusely present in this study, the expression frequencies in the $3 \mathrm{~mm}$ TMA core may have been underestimated. This hypothesis was supported by a recent study which demonstrated that K19 expression in biopsy specimens for HCC taken prior to radiofrequency ablation is extremely low (4.1\%) (8). Assessment of a biomarker in a small TMA tissue core may not accurately reflect the assessment that would be obtained from a whole section analysis due to intratumoral heterogeneity (30). Similar to a number of other solid tumors, HCCs are characterized by a high degree of tumor cell heterogeneity. Our results demonstrated that the intratumoral heterogeneity and the size of tissue sections have a great impact on the results of K19 and K7 expression in HCC.

We found that K19 expression in HCC was significantly associated with the histological grade and serum AFP level. These findings are consistent with observations reported by other studies $(7,18,28-30)$. A correlation between K19 expression and high AFP levels and high-grade HCC has been demonstrated by Yuan et al (29). Similarly, serum AFP concentration in patients with K19-positive HCC increases along with K19 immunostaining grades, suggesting a correlation between serum AFP and K19 expression (28). Uenishi et al also demonstrated that K19 expression correlates with poor differentiation of HCC (31). Since K19 expression was associated with high tumor grade and high AFP levels in this study, the results of $\mathrm{K} 19$ as a prognostic factor for HCC is reasonable. The prognosis of patients with $\mathrm{K} 19$-positive $\mathrm{HCC}$ is considered to be worse than those with pure $\operatorname{HCC}(9,21,28)$. In this study, K19 expression in HCC was not an independent predictor of the overall rate of survival in all patients with HCC. However, we found that K19 expression was associated with poor survival in patients with non-viral HCC. Based on the limited number of cases, insufficient follow-up periods, different etiologies and genetic backgrounds of HCC, a definite conclusion on the effect of K19 on the prognosis of HCC patients could not be reached. A longer term follow-up with a larger cohort and strictly categorized tumors is required to adequately define the clinical and biological behavior of this tumor.

In conclusion, our study indicates that K19 expression is rare in DNs, well-known precancerous HCC lesions, but occurs predominantly in distinctly nodular small HCC. Although we cannot conclude whether the K19-positive HCCs originated from pre-existing cancer stem cells in HCC or from dedifferentiation of HCC cells, the present results suggest that the K19 phenotype might be an acquired feature of carcinoma cells during HCC progression.

\section{Acknowledgements}

This study was supported by the National Research Foundation of Korea Grant funded by the Korea government
(No. 2011-0028223) and by the grant of Post-Doc. Program, Chonbuk National University (2011).

\section{References}

1. Parkin DM, Bray F, Ferlay J and Pisani P: Global cancer statistics, 2002. CA Cancer J Clin 55: 74-108, 2005.

2. Ferlay J, Shin HR, Bray F, Forman D, Mathers C and Parkin DM: Estimates of worldwide burden of cancer in 2008: GLOBOCAN 2008. Int J Cancer 127: 2893-2917, 2010.

3. Park YN: Update on precursor and early lesions of hepatocellular carcinomas. Arch Pathol Lab Med 135: 704-715, 2011.

4. Theise ND, Curado MP, Franceschi S, Hytiroglou P, Kudo M, Park YN, Sakamoto $M$, Torbenson $M$ and Wee A: Hepatocellular carcinoma. In: WHO Classification Of Tumours Of The Digestive System. Bosman FT, Carneiro F, Hruban RH and Theise ND (eds). 4th edition. IARC Press, Lyon, pp205-216, 2010.

5. Durnez A, Verslype C, Nevens F, Fevery J, Aerts R, Pirenne J, Lesaffre E, Libbrecht L, Desmet V and Roskams T: The clinicopathological and prognostic relevance of cytokeratin 7 and 19 expression in hepatocellular carcinoma. A possible progenitor cell origin. Histopathology 49: 138-151, 2006.

6. Zhuang PY, Zhang JB, Zhu XD, Zhang W, Wu WZ, Tan YS, Hou J, Tang ZY, Qin LX and Sun HC: Two pathologic types of hepatocellular carcinoma with lymph node metastasis with distinct prognosis on the basis of CK19 expression in tumor. Cancer 112: 2740-2748, 2008.

7. Kim H, Choi GH, Na DC, Ahn EY, Kim GI, Lee JE, Cho JY, Yoo JE, Choi JS and Park YN: Human hepatocellular carcinomas with 'Stemness'-related marker expression: keratin 19 expression and a poor prognosis. Hepatology 54: 1707-1717, 2011.

8. Tsuchiya K, Komuta M, Yasui Y, Tamaki N, Hosokawa T, Ueda K, Kuzuya T, Itakura J, Nakanishi H, Takahashi Y, Kurosaki M, et al: Expression of keratin 19 is related to high recurrence of hepatocellular carcinoma after radiofrequency ablation. Oncology 80: 278-288, 2011

9. Yang XR, Xu Y, Yu B, Zhou J, Qiu SJ, Shi GM, Zhang BH, Wu WZ, Shi YH, Wu B, Yang GH, Ji Y and Fan J: High expression levels of putative hepatic stem/progenitor cell biomarkers related to tumour angiogenesis and poor prognosis of hepatocellular carcinoma. Gut 59: 953-962, 2010.

10. Andersen JB, Loi R, Perra A, Factor VM, Ledda-Columbano GM, Columbano A and Thorgeirsson SS: Progenitor-derived hepatocellular carcinoma model in the rat. Hepatology 51: 1401-1409, 2010.

11. Edge SB, Byrd DR, Compton CC, Fritz AG, Greene FL and Trotti A (eds): AJCC Cancer Staging Manual. 7th edition. Springer, New York, 2010.

12. Choi HN, Bae JS, Jamiyandorj U, Noh SJ, Park HS, Jang KY, Chung MJ, Kang MJ, Lee DG and Moon WS: Expression and role of SIRT1 in hepatocellular carcinoma. Oncol Rep 26: 503-510, 2011.

13. Moll R, Franke WW, Schiller DL, Geiger B and Krepler R: The catalog of human cytokeratins: patterns of expression in normal epithelia, tumors and cultured cells. Cell 31: 11-24, 1982.

14. Lai YS, Thung SN, Gerber MA, Chen ML and Schaffner F: Expression of cytokeratins in normal and diseased livers and in primary liver carcinomas. Arch Pathol Lab Med 113: 134-138, 1989.

15. Johnson DE, Herndier BG, Medeiros LJ, Warnke RA and Rouse RV: The diagnostic utility of the keratin profiles of hepatocellular carcinoma and cholangiocarcinoma. Am J Surg Pathol 12: 187-197, 1988.

16. Libbrecht L, Desmet V, Van Damme B and Roskams T: The immunohistochemical phenotype of dysplastic foci in human liver: correlation with putative progenitor cells. J Hepatol 33: 76-84, 2000.

17. Van Eyken P, Sciot R, Paterson A, Callea F, Kew MC and Desmet VJ: Cytokeratin expression in hepatocellular carcinoma: an immunohistochemical study. Hum Pathol 19: $562-568,1988$.

18. Ding SJ, Li Y, Tan YX, Jiang MR, Tian B, Liu YK, Shao XX, Ye SL, Wu JR, Zeng R, Wang HY, Tang ZY and Xia QC: From proteomic analysis to clinical significance: overexpression of cytokeratin 19 correlates with hepatocellular carcinoma metastasis. Mol Cell Proteomics 3: 73-81, 2004. 
19. Limaye PB, Bowen WC, Orr AV, Luo J, Tseng GC and Michalopoulos GK: Mechanisms of hepatocyte growth factor-mediated and epidermal growth factor-mediated signaling in transdifferentiation of rat hepatocytes to biliary epithelium. Hepatology 47: 1702-1713, 2008.

20. Nishikawa Y, Doi Y, Watanabe H, Tokairin T, Omori Y, Su M, Yoshioka T and Enomoto K: Transdifferentiation of mature rat hepatocytes into bile duct-like cells in vitro. Am J Pathol 166: 1077-1088, 2005.

21. Yoneda N, Sato Y, Kitao A, Ikeda H, Sawada-Kitamura S, Miyakoshi M, Harada K, Sasaki M, Matsui O and Nakanuma Y: Epidermal growth factor induces cytokeratin 19 expression accompanied by increased growth abilities in human hepatocellular carcinoma. Lab Invest 91: 262-272, 2011.

22. Zen C, Zen Y, Mitry RR, Corbeil D, Karbanová J, O'Grady J, Karani J, Kane P, Heaton N, Portmann BC and Quaglia A: Mixed phenotype hepatocellular carcinoma after transarteria chemoembolization and liver transplantation. Liver Transpl 17: 943-954, 2011

23. Ravaioli M, Grazi GL, Ercolani G, Fiorentino M, Cescon M, Golfieri R, Trevisani F, Grigioni WF, Bolondi L and Pinna AD: Partial necrosis on hepatocellular carcinoma nodules facilitates tumor recurrence after liver transplantation. Transplantation 78 : 1780-1786, 2004.

24. Nishihara Y,AishimaS,Kuroda Y,IguchiT,TaguchiK,Asayama Y, Taketomi A, Kinukawa N, Honda $\mathrm{H}$ and Tsuneyoshi M: Biliary phenotype of hepatocellular carcinoma after preoperative transcatheter arterial chemoembolization. J Gastroenterol Hepatol 23: 1860-1868, 2008.
25. Shackleton M, Quintana E, Fearon ER and Morrison SJ: Heterogeneity in cancer: cancer stem cells versus clonal evolution. Cell 138: 822-829, 2009.

26. Bomken S, Fiser K, Heidenreich $\mathrm{O}$ and Vormoor $\mathrm{J}$ : Understanding the cancer stem cell. Br J Cancer 103: 439-445, 2010.

27. Aishima S, Nishihara Y, Kuroda Y, Taguchi K, Iguchi T, Taketomi A, Maehara Y and Tsuneyoshi M: Histologic characteristics and prognostic significance in small hepatocellular carcinoma with biliary differentiation: subdivision and comparison with ordinary hepatocellular carcinoma. Am J Surg Pathol 31: 783-91, 2007.

28. Lu XY, Xi T, Lau WY, Dong H, Zhu Z, Shen F, Wu MC and Cong WM: Hepatocellular carcinoma expressing cholangiocyte phenotype is a novel subtype with highly aggressive behavior. Ann Surg Oncol 18: 2210-2217, 2011.

29. Yuan RH, Jeng YM, Hu RH, Lai PL, Lee PH, Cheng CC and Hsu HC: Role of p53 and $\beta$-catenin mutations in conjunction with CK19 expression on early tumor recurrence and prognosis of hepatocellular carcinoma. J Gastrointest Surg 15: 321-329, 2011.

30. Simon R and Sauter G: Tissue microarrays for miniaturized high-throughput molecular profiling of tumors. Exp Hematol 30: $1365-1372,2002$

31. Uenishi T, Kubo S, Yamamoto T, Shuto T, Ogawa M, Tanaka H, Tanaka S, Kaneda K and Hirohashi K: Cytokeratin 19 expression in hepatocellular carcinoma predicts early postoperative recurrence. Cancer Sci 94: 851-857, 2003. 